\title{
Plasma and salivary concentrations of erythromycin after administration of three different formulations
}

\author{
JOHN HENRY* \\ PAUl TURNer* \\ M.B., M.R.C.P. \\ B.SC., M.D., F.R.C.P. \\ MARTIN GARLAND $\dagger$ \\ M.B., M.R.C.P., M.R.C.G.P. \\ FRANCOIS ESMIEU $\ddagger$ \\ M.D.
*Department of Clinical Pharmacology, St Bartholomew's Hospital, London EC1A 7BE, $\dagger$ Roussel Laboratories Limited, Roussel House, Wembley Park, Middlesex HA9 ONF, and $\ddagger$ Institut Roussel Uclaf

\begin{abstract}
Summary
In a 6-volunteer cross-over study the pharmacokinetics of 3 erythromycin preparations were compared. A single oral dose of $\mathbf{5 0 0} \mathrm{mg}$ of each preparation was administered at each occasion and the levels measured in timed samples of plasma and saliva. Markedly higher blood concentrations of the estolate and propionate were obtained compared to the stearate. Comparison of serum and plasma concentration of the drugs from each split sample showed no significant differences. Plasma concentrations always exceeded those in saliva but for any one preparation a similar ratio was obtained at different times. This may be useful to ascertain compliance and to measure concentration of the compounds where direct measurement in plasma is not practicable.
\end{abstract}

\section{Introduction}

Erythromycin has an important place in treating many infections, particularly those due to Gram positive organisms, Mycoplasma, Chlamydia and anaerobes and in general, apart from the estolate ester, has a relatively wide safety margin (Lacey, 1977). Several esters as well as the base have been used clinically, some giving earlier, higher and more consistent plasma concentrations than others. The authors have compared the absorption of erythromycin in normal human subjects following administration of identical doses of the estolate, propionate and stearate, and have measured the plasma/salivary ratios of erythromycin in order to determine if salivary estimations provide a reliable guide to its plasma concentrations.

\section{Experimental methods}

Six volunteers ( 3 female, 3 male) aged 20-30 years whose weights and heights were within normal limits took part in the study. Clinical examination and laboratory tests of haematology, liver and renal function had shown no abnormality, and pregnancy tests in females were negative. No drugs had been taken for one week before the dates of administration of the test substances and no alcohol was permitted during the study period. Subjects were allowed a light breakfast, following an overnight fast, at least $2 \mathrm{hr}$ before drug ingestion and no food was then permitted until $3 \mathrm{hr}$ after. Subjects remained supine during the first $4 \mathrm{hr}$ after ingestion of the drug, and during the remainder of the day abstained from strenuous or athletic activities.

Three test preparations were used: erythromycin estolate capsules (Ilosone) $2 \times 250 \mathrm{mg}$, erythromycin propionate capsules (Propiocine) $1 \times 500 \mathrm{mg}$ and erythromycin stearate tablets (Erythrocin) $1 \times 500$ mg. Treatment was assigned randomly on the basis of 2 Latin squares so that each volunteer received each treatment separately on one of 3 occasions at weekly intervals at 9 a.m. Plasma samples were collected before and $20,40,60$, $90 \mathrm{~min}$, and 2, 4, 6, 8, 12 and $24 \mathrm{hr}$ after administration.

Each of the timed blood samples was divided into 2 groups. One was centrifuged at $4^{\circ} \mathrm{C}$ immediately for $15 \mathrm{~min}$ at $4000 \mathrm{rev} / \mathrm{min}$ and the separated plasma removed and frozen at $-25^{\circ} \mathrm{C}$. The remainder of the sample was allowed to coagulate at room temperature and then centrifuged for $15 \mathrm{~min}$ at $4^{\circ} \mathrm{C}$ at $4000 \mathrm{rev} / \mathrm{min}$ and the extracted serum frozen at $-25^{\circ} \mathrm{C}$.

Unstimulated saliva was collected at $1,2,4,6$, and $8 \mathrm{hr}$ after ingestion of the drug.

Assay

Erythromycin activity was determined on the 
various samples by a cup plate assay using Bacillus subtilis ATCC 6633 as test organism. The samples (plasma, serum and saliva) as well as a standard sample of erythromycin base were diluted in $0 \cdot 1$ $\mathrm{mol} / 1$ phosphate-buffered saline $\mathrm{pH} 8 \cdot 0$. Standard curves were established by serial dilution of standard erythromycin base, with a sensitivity range of 0.04 to $0.32 \mu \mathrm{g} / \mathrm{ml}$.
Statistical methods

The pharmacokinetic evaluations were made $\underset{\propto}{\stackrel{\infty}{\infty}}$ using a one-compartment open model, with first..order absorption and elimination processes. $A \Rightarrow$ programme package of the Department of In-? formatique Roussel Uclaf (DIRU) was used to fit? individual serum/plasma concentrations. The follow-흠 ing pharmacokinetic parameters, peak level, time

TABLE 1. Plasma and saliva concentrations of erythromycin $(\mu \mathrm{g} / \mathrm{ml})$ mean $( \pm$ s.e. mean $)(n=6)$

\begin{tabular}{lllll}
\hline & & Propionate & Estolate & Stearate \\
\hline Plasma & & & \\
Saliva & 2 & & & \\
& & $3.14(0.56)$ & $3.03(0.41)$ & $0.91(0.28)$ \\
& 4 & $0.71(0.28)$ & $0.40(0.18)$ & $0.20(0.09)$ \\
& & $2.31(0.40)$ & $2.69(0.31)$ & $0.87(0.15)$ \\
& 6 & $0.21(0.06)$ & $0.25(0.08)$ & $0.16(0.04)$ \\
& & $1.47(0.32)$ & $1.82(0.34)$ & $0.35(0.07)$ \\
& & $0.12(0.02)$ & $0.15(0.04)$ & $0.09(0.02)$ \\
& & $0.89(0.22)$ & $1.02(0.19)$ & $0.13(0.02)$ \\
& 12 & $0.09(0.02)$ & $0.09(0.02)$ & $0.07(0.01)$ \\
& $0.28(0.07)$ & $0.42(0.07)$ & $0.06(0.001)$ \\
& $0.06(0.00)$ & $0.07(0.01)$ & $0.07(0.01)$ \\
\hline
\end{tabular}

Plasma and serum concentrations mean ( \pm s.e. mean) kinetic parameters for the 3 compounds

\begin{tabular}{lccc}
\hline $\begin{array}{l}\text { Peak level } \\
(\mu \mathrm{g} / \mathrm{ml})\end{array}$ & $3.40(0.78)$ & $3.00(0.55)$ & $1.23(0.37)$ \\
$\begin{array}{l}\text { Time to peak } \\
(\mathrm{hr})\end{array}$ & $1.58(0.15)$ & $2.08(0.97)$ & $2.92(0.49)$ \\
$\begin{array}{c}\text { Area under curve } \\
\quad(\mathrm{mg} / \mathrm{ml} \text { hr) }\end{array}$ & $17.98(5.04)$ & $18.64(4.37)$ & $4.70(1.63)$ \\
$\begin{array}{c}\text { Elimination half-life } \\
(\mathrm{hr})\end{array}$ & $2.63(0.29)$ & $2.95(0.28)$ & $1.18(0.19)$ \\
\hline
\end{tabular}

TABLE 2. Ratio of plasma to saliva concentrations (mean $\% \pm$ s.e. mean). Results subjected to computer analysis

\begin{tabular}{|c|c|c|c|c|c|}
\hline & $2 \mathrm{hr}$ & $4 \mathrm{hr}$ & $6 \mathrm{hr}$ & Overall mean & $r$ \\
\hline \multirow{2}{*}{ Propionate } & $12 \cdot 54 \pm 3.00$ & $7 \cdot 62 \pm 1 \cdot 20$ & $8 \cdot 29 \pm 1 \cdot 80$ & $10 \cdot 3 \pm 1 \cdot 3$ & 0.69 \\
\hline & $(4 \cdot 3-20 \cdot 8)$ & $(4 \cdot 3-10 \cdot 9)$ & $(3 \cdot 3-13 \cdot 3)$ & $(7 \cdot 5-13 \cdot 1)$ & $P<0.01$ \\
\hline \multirow{2}{*}{ Estolate } & $7 \cdot 38 \pm 1 \cdot 42$ & $6.46 \pm 1.00$ & $7 \cdot 28 \pm 0.65$ & $7 \cdot 5 \pm 0 \cdot 7$ & $0 \cdot 86$ \\
\hline & $(3 \cdot 4-11 \cdot 3)$ & $(3 \cdot 7-9 \cdot 3)$ & $(5 \cdot 5-9 \cdot 1)$ & $(5 \cdot 9-9 \cdot 0)$ & $P<0.01$ \\
\hline \multirow{2}{*}{ Stearate } & $24 \cdot 88 \pm 6 \cdot 42$ & $17 \cdot 10 \pm 3 \cdot 61$ & $28 \cdot 52 \perp 6 \cdot 20$ & $23 \cdot 5 \div 3 \cdot 2$ & 0.90 \\
\hline & $(7 \cdot 1-42 \cdot 7)$ & $(7 \cdot 1-27 \cdot 1)$ & $(11 \cdot 3-45 \cdot 7)$ & $(16 \cdot 6-30 \cdot 4)$ & $P<0.01$ \\
\hline
\end{tabular}

The figures in brackets show the limits of $95 \%$ confidence interval. $r$ correlation coefficient between saliva and plasma values $\frac{0}{\Phi}$ 
to peak, area under curve and elimination half-life were subjected to statistical comparisons.

The one-factor analysis of variance with repeated measures was used to compare the pharmacokinetic parameters of the drugs. Since a suitable choice of 2 Latin squares provided a balanced design with respect to residual effects, the analysis followed the method of Williams, where the direct effect of a treatment is adjusted so as to remove residual effects from the previous period (Cochian and Cox, 1957).

\section{Results}

Table 1. This shows plasma and salivary concentrations of the 3 preparations.

Erythromycin propionate reached a peak of $3.4 \mu \mathrm{g} / \mathrm{ml} 1.58 \mathrm{hr}$ after ingestion, the estolate peaking at a lower concentration of $3.0 \mu \mathrm{g} / \mathrm{ml}$ and requiring a longer time to reach this value, with a mean of $2.08 \mathrm{hr}$. The stearate showed markedly lower blood concentration with a mean peak of $1.23 \mu \mathrm{g} / \mathrm{ml}$ and $2.92 \mathrm{hr}$ to this concentration. The area under curve values for the antibiotics were comparable for the propionate and estolate with a mean of $17.98 \mu \mathrm{g} / \mathrm{ml} / \mathrm{hr}$ and $18.64 \mu \mathrm{g} / \mathrm{ml} / \mathrm{hr}$ respectively, whereas the stearate was only $4.7 \mu \mathrm{g} / \mathrm{ml} / \mathrm{hr}$. Mean elimination half-lives were $2.63 \mathrm{hr}, 2.95 \mathrm{hr}$ and $1.18 \mathrm{hr}$ for the propionate, estolate and stearate respectively.

Table 2. The ratio of plasma/saliva and serum/ saliva concentrations for the propionate and estolate showed a mean maximum value at $2 \mathrm{hr}$ of 12.54 and 7.38 dropping to 8.29 and 7.28 at $6 \mathrm{hr}$ respectively. The stearate ratio was markedly higher, 24.88 at $2 \mathrm{hr}$ and rising to 28.52 at $6 \mathrm{hr}$.

The mean values for the 3 compounds in plasma, serum and saliva are compared in Figures 1 and 2.

\section{Discussion}

These results confirm those of previous investigations and demonstrate the markedly higher systemic availability of erythromycin from the estolate and propionate compared with the stearate esters. It has been shown in the literature that, using erythromycin esters, the drug circulates in the blood partly as ester and partly as base. Therefore, the in vivo activity must not be considered in terms

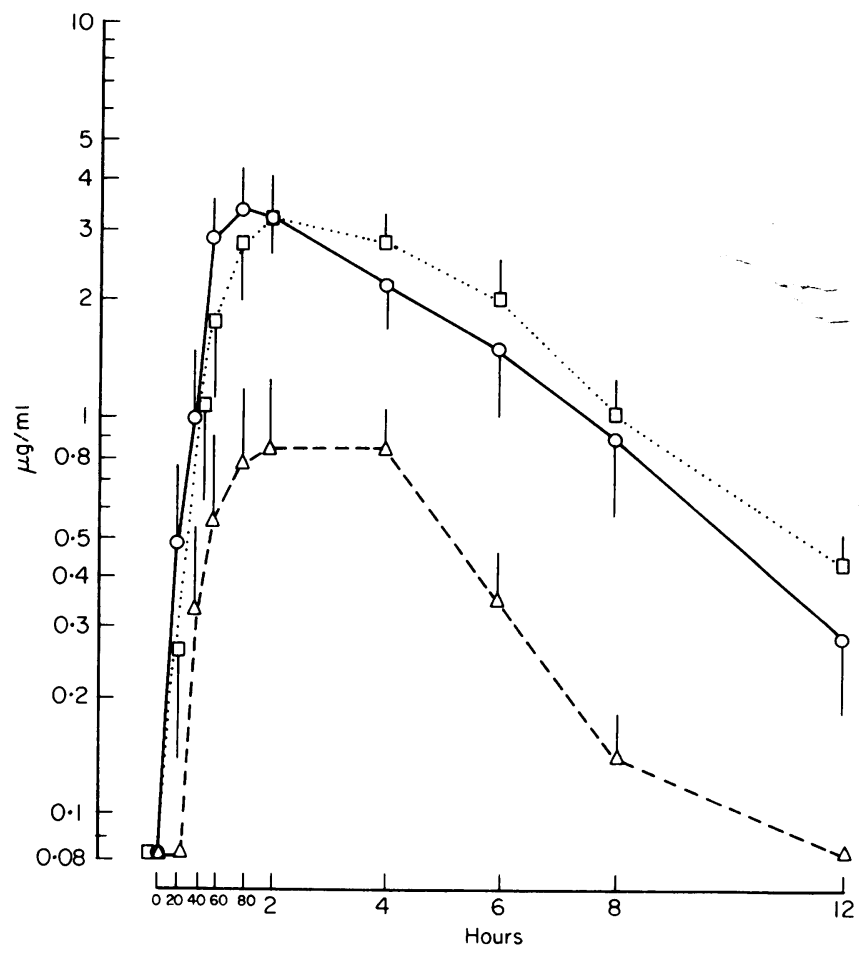

FIG. 1. Mean plasma erythromycin concentrations. $0-0$ propionate, $\square \ldots \square$ estolate, $\Delta---\Delta$ stearate. 
of that found in in vitro (Tardrew, Mao and Kenny, 1969).

The kinetic constants obtained are similar to those demonstrated in earlier studies (Stephens et al., 1969; Wiegand, 1972; Griffith, 1958).

The serum/plasma ratios of erythromycin concentrations showed a reasonable degree of consistency with those in the literature, i.e. approximately

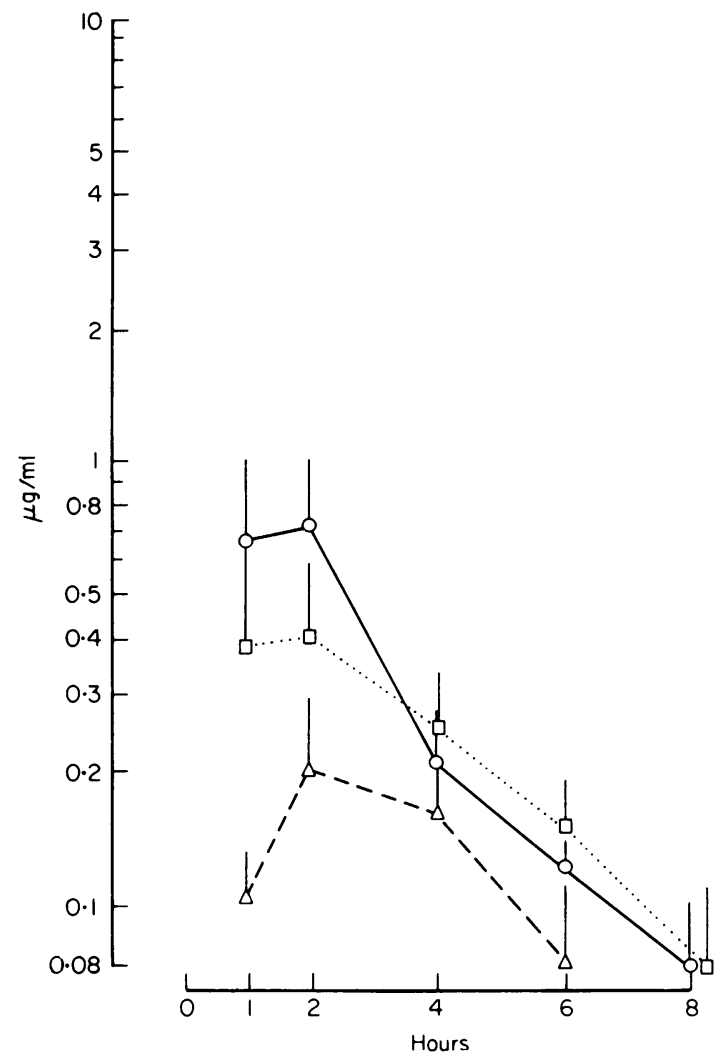

FIG. 2. Mean salivary erythromycin concentrations. ○-O propionate, $\square \ldots \square$ estolate, $\triangle--\triangle$ stearate.
$10 \%$ after administration of each of the 3 preparations. The stearate ratio was greater than that of the other esters although the total count was smaller, partly owing to the fact that erythromycin propionate and estolate circulate as the esters and that there may therefore be a difference in their distribution in the tissues.

The above indicates not only that satisfactory therapeutic concentrations are reached in the saliva, particularly after administration of the propionate and estolate but also that salivary drug concentrations may be used as an alternative to plasma concentration when monitoring the course of treatment with erythromycin in conditions where it is imperative rapidly to achieve adequate therapeutic concentrations of drug in tissues. This is subject to the important limitation, however, derived from observations with the lipid soluble drug propranolol (Kaye et al., 1977), that buccal contamination by a drug may invalidate salivary estimations carried out on samples collected less than $2 \mathrm{hr}$ after oral ingestion.

\section{References}

Cochian, W.G. \& Cox, G.M. (1957) Experimental Designs. 2nd Edn, John Wiley and Sons Inc., London.

GriffithS, R.S. (1958/59) Laboratory and clinical studies with erythromycin propionate. Antibiotics Annual, p. 364.

Kaye, C.M., Orton, D., Taylor, E.A. \& Brunell, (1977) Plasma-salivary ratios of acebutolol, and propranolol. British Journal of Clinical Pharmacology; 4, 724.

LACEY, R.W. (1977) A new look at erythromycin. Postgraduate Medical Journal, 53, 195.

Stephens, V.C., Pugh, C.T., Davis, N.E., Hoehn, M.M., Ralston, S., Sparks, M.C. \& ThOMPKins, L. (1969) A study of the behaviour of propionyl erythromycin in blood by a new chromatographic method. Journil of Antibiotics, 22, 551.

TARDREW, P.L., MaO, J.C.H. \& KenNy, D. (1969) Antibacterial activity of 2 '-esters of erythromycin. Afplied Microbiology, 18, 159.

Wiegand, R.C. \& Chun, A.H.C. (1972) Serum protein binding of erythromycin and erythromycin $2^{\prime}$-propionate ester. Journal of Pharmaceutical Sciences, 61, 425. 